\title{
Determination of human ketone body kinetics using stable-isotope labelled tracers
}

\author{
M. Beylot ${ }^{1}$, B. Beaufrère ${ }^{1}$, S. Normand ${ }^{1}$, J. P. Riou ${ }^{1}$, R. Cohen $^{2}$ and R. Mornex ${ }^{1}$ \\ ${ }^{1}$ INSERM U.197, Faculté de Médecine Alexis Carrel, Lyon, and \\ ${ }^{2}$ Service of Radioanalyse, Hôpital Neurocardiologique, Bron, France
}

Summary. In order to avoid the use of radioactive tracers for the determination of human ketone body turnover, we have developed a method using a primed-continuous infusion of ${ }^{13} \mathrm{C}$-labelled acetoacetate or D- $\beta$-hydroxybutyrate. Determination of the mole percent enrichment of blood acetoacetate and D- $\beta$-hydroxybutyrate was performed by gas chromatography/mass spectrometry. In the post-absorptive state, the mean total ketone body appearance rate, determined in four subjects, was $3.74 \mu \mathrm{mol} \cdot \mathrm{kg}^{-1} \cdot \mathrm{min}^{-1}$ using $\left[3,4-^{13} \mathrm{C} 2\right]$ acetoacetate and $2.76 \mu \mathrm{mol} \cdot \mathrm{kg}^{-1} \cdot \mathrm{min}^{-1}$ using $\left[3{ }^{13} \mathrm{C}\right] \mathrm{D}-\beta$-hydroxybutyrate, values in agreement with those reported in studies with ${ }^{14} \mathrm{C}$-labelled tracers. In order to evaluate the usefulness of the method for determination of ketone body kinetics in non steady-state conditions, we infused four subjects with natural sodium acetoacetate and calculated the isotopically determined total ketone body appearance rate using a single compartment model (volume of distribution $0.201 / \mathrm{kg}$; functional pool fraction: 1 ). During the tests with $\left[3,4-{ }^{13} \mathrm{C} 2\right]-$ acetoacetate, the actual infusion rates of natural acetoacetate were $7.3 \pm 0.3,14.6 \pm 0.8,21.9 \pm 1.2$ and $10.9 \pm 0.6 \mathrm{umol}$. $\mathrm{kg}^{-1} \cdot \mathrm{min}^{-1}$ whereas the corresponding isotopically determined total ketone body appearance rates were respectively $9.2 \pm 1.0, \quad 16.3 \pm 0.7, \quad 23.1 \pm 1.1$ and $10.7 \pm 0.8$ umol $\mathrm{kg}^{-1} \cdot \mathrm{min}^{-1}$. During the tests with $\left[3{ }^{13} \mathrm{C}\right] \mathrm{D}-\beta$-hydroxybutyrate, the actual infusion rates were $8.4 \pm 0.5,16.8 \pm 0.9,25.2 \pm$ 1.4 and $12.6 \pm 0.8 \mu \mathrm{mol} \cdot \mathrm{kg}^{-1} \cdot \mathrm{min}^{-1}$, and the isotopically determined appearance rates respectively $11.1 \pm 0.7,16.7 \pm 0.7$, $25.0 \pm 1.1$ and $11.1 \pm 0.7 \mu \mathrm{mol} \cdot \mathrm{kg}^{-1} \cdot \mathrm{min}^{-1}$. Thus, using either tracer we found a good agreement between acetoacetate infusion rate and tracer-determined appearance rate of ketone bodies. In conclusion, the present method may be used to determine human ketone body kinetics under steady-state and non steady-state conditions.

Key words: Acetoacetate, $\beta$-hydroxybutyrate, ketogenesis, ketone body kinetics, stable isotopes, mass spectrometry.
Blood ketone bodies (acetoacetate and D- $\beta$-hydroxybutyrate) are important metabolic substrates, since they can act as oxidative fuels, as lipogenic precursors and as regulators of metabolism [1]. An understanding of their in vivo metabolism requires the determination of their appearance and disappearance rates. Such determinations usually are performed using the isotope dilution method with ${ }^{14} \mathrm{C}$-labelled acetoacetate or D- $\beta$-hydroxybutyrate [2-7]; these methods have been validated for both steady- and non steady-state conditions [4, 5, 8]. However, radioactive tracers expose patients to the hazards of radiation, which makes their use undesirable in adults and precludes their utilisation in children or pregnant women. Moreover, the use of radioactive isotopic tracers in normal subjects is not authorized in some countries. The use of stable isotopes avoids these limitations. Recently, Miles et al. [9] have reported a method for the determination of ketone body turnover in dogs using the $\gamma$-butyldimethylsilyl derivatives of ke- tone bodies and stable-isotope labelled tracers. In the present report we describe a method using trimethylsilyl derivatives of ketone bodies and gas-chromatography/ mass spectrometry (GC/MS) for determination of the enrichment of blood acetoacetate and D- $\beta$-hydroxybutyrate during infusion of ${ }^{13} \mathrm{C}$-labelled tracers, and the application of the method for the determination of ketone body flux under both steady- and non steady-state conditions in humans.

\section{Subjects and methods}

Four normal subjects [ 3 men and 1 woman aged 29 to 40 years (body mass index 20.2 to 24.8)] volunteered for the study after full explanation of the purpose, nature and possible risks of the investigations. All these in vivo studies were performed in accordance with the principles of the Declaration of Helsinki. The subjects were instructed to consume their usual diet throughout the study. All tests were performed in the post-absorptive state. Each subject had two tests, one 
with $\left[3-{ }^{13} \mathrm{C}\right] \mathrm{D}-\beta$-hydroxybutyrate and the other with $\left[3,4-{ }^{13} \mathrm{C} 2\right]$ acetoacetate, with an interval of at least one week between tests. On the morning of the test an indwelling catheter was placed into an antecubital vein for the infusions; to obtain arterialized blood samples another catheter was inserted in a retrograde manner in a vein of the opposite hand kept at $60^{\circ} \mathrm{C}$ in a warming box [10]. Patency of all catheters was maintained by a slow infusion of isotonic saline. After $30 \mathrm{~min}$ of bed rest, three blood samples were collected at $5 \mathrm{~min}$ intervals. A priming dose (10 times the infusion rate over $1 \mathrm{~min}$ ) of the tracer was then injected followed by a constant infusion over $165 \mathrm{~min}\left(\left[3-{ }^{-13} \mathrm{C}\right] \mathrm{D}-\beta\right.$-hydroxybutyrate: $0.08-0.12 \mu \mathrm{mol} \cdot \mathrm{kg}^{-1} \cdot \mathrm{min}^{-1}$ or $\left[3,4-{ }^{13} \mathrm{C} 2\right]$ acetoacetate $\left.0.144-0.223 \mu \mathrm{mol} \cdot \mathrm{kg}^{-1} \cdot \mathrm{min}^{-1}\right)$. Tracers were diluted with sodium chloride $(154 \mathrm{mmol} / \mathrm{l})$ prior to infusion with a previously calibrated pump (Bioblock Scientific, Strasbourg, France). Following a basal equilibrating period of $90 \mathrm{~min}$, natural sodium acetoacetate was infused with a peristaltic pump (Dubernard Hospital, Bordeaux, France) at four successive rates $(8,16,24$ and $12 \mu \mathrm{mol}$. $\mathrm{kg}^{-1} \cdot \mathrm{min}^{-1}$, each for $15 \mathrm{~min}$. Blood samples were collected before the infusion of natural sodium acetoacetate (60-90 $\mathrm{min}$ ), at each infusion step, and 10 and $15 \mathrm{~min}$ afterwards. Aliquots of the tracers were collected before and after the infusion in order to check concentration and stability. No spontaneous degradation of either tracer was ob-

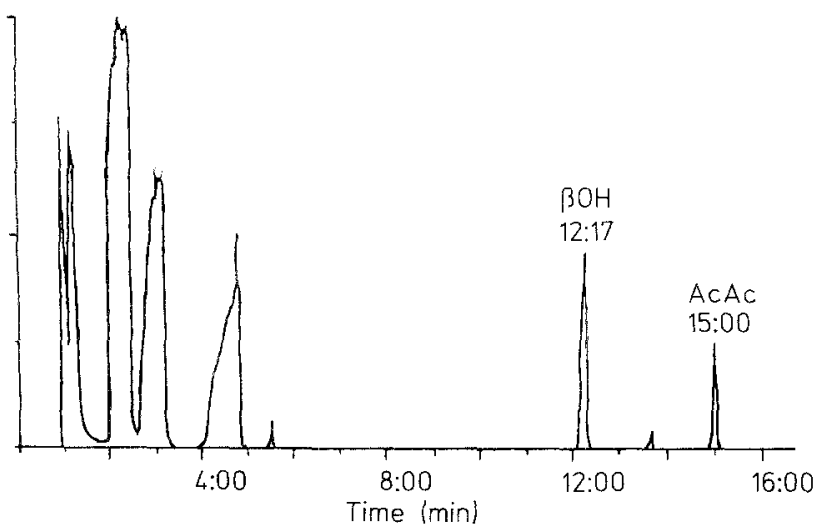

Fig. 1. Total ion chromatogram obtained with the trimethylsilyl derivatives of a mixed standard of acetoacetate and D- $\beta$-hydroxybutyrate. The peaks observed during the first $5 \mathrm{~min}$ are solvents and reagents. D- $\beta$-hydroxybutyrate eluates next, followed by the two peaks of acetoacetate served (data not shown). The infusion rates of natural acetoacetate were determined from the concentration and volume of acetoacetate delivered during each period of infusion.

\section{Preparation of infusates}

$\left[3-{ }^{13} \mathrm{C}\right]$ ethyl acetoacetate ( $99 \%$ atom excess) and $\left[3,4-{ }^{13} \mathrm{C} 2\right]$ ethyl acetoacetate ( $99 \%$ atom excess) were obtained from the "Commissariat à l'Energie Atomique" (Gif-sur-Yvette, France). For the preparation of labelled acetoacetate $\left[3,4-{ }^{13} \mathrm{C} 2\right]$ ethyl-acetoacetate was hydrolysed by incubation at $40^{\circ} \mathrm{C}$ during $60 \mathrm{~min}$ with $10 \%$ excess of $1 \mathrm{~N} \mathrm{NaOH}$. After neutralisation with $1 \mathrm{~N} \mathrm{HCl}$, the solution was washed three times with diethylether (Merck, Darmstadt, FRG), flushed with $\mathrm{N}_{2}$ and stored at $-80^{\circ} \mathrm{C}$ until use. Natural sodium acetoacetate was prepared from ethyl-acetoacetate (Merck) by the same procedure, adjusting the $\mathrm{pH}$ to 7.40 prior to storage at $-80^{\circ} \mathrm{C}$. (Yield $90-99 \%$ ).

For the preparation of labelled D- $\beta$-hydroxybutyrate, $\left[3-{ }^{13} \mathrm{C}\right]$ ethyl acetoacetate was first hydrolysed to acetoacetate as described. $\left[3-{ }^{13} \mathrm{C}\right]$ acetoacetate was then converted to $\left[3-{ }^{13} \mathrm{C}\right] \mathrm{D}-\beta$-hydroxybutyrate using $\beta$-hydroxybutyrate dehydrogenase (Boehringer, Mannheim, FRG) and NADH (Boehringer) in phosphate buffer $(10 \mathrm{mmol} / \mathrm{l}$, $\mathrm{pH} 6.80)$. The reaction was followed by measuring the decrease in optical density at $340 \mathrm{~nm}$. (Yield $>90 \%$ after $48 \mathrm{~h}$ at room temperature). $\beta$-hydroxybutyrate dehydrogenase was removed by ultrafiltration (PM 10, Amicon Corporation, Lexington, MA, USA) and the filtrate subjected to anion exchange chromatography (AG1X8 in the $\mathrm{HCO}_{3}^{-}$ form, Biorad, Richmond, CA, USA). NAD, acetoacetate and D- $\beta$-hydroxybutyrate were eluted with $\mathrm{NaHCO}_{3}(10 \mathrm{~g} / 1)$, NADH remaining on the column. The eluate was concentrated and acidified to $\mathrm{pH} 1$ with HCL and D- $\beta$-hydroxybutyrate extracted with diethylether. Finally, the organic phase was evaporated in a vial containing $\mathrm{NaHCO}_{3}$ $(20 \mathrm{ml}, 10 \mathrm{~g} / \mathrm{l})$. The purified sample contained no detectable trace of NAD or NADH. The small amount of acetoacetate remaining with $\mathrm{D}-\beta$-hydroxybutyrate was destroyed by heating at $100^{\circ} \mathrm{C}$ for $1 \mathrm{~h}$ and flushing with $\mathrm{N}_{2}$. (Overall yield 75-80\%). All infusates were passed through a $0.22 \mu \mathrm{m}$ Millipore filter following preparation. The absence of pyrogen was checked by the standard method of measurement of rabbit body temperature after intravenous injection.

\section{Analytical procedures}

Acetoacetate, D- $\beta$-hydroxybutyrate and glucose were assayed in whole blood after deproteinization by $6 \%$ ice cold perchloric acid using standard enzymatic methods as described previously [11]. Ace-
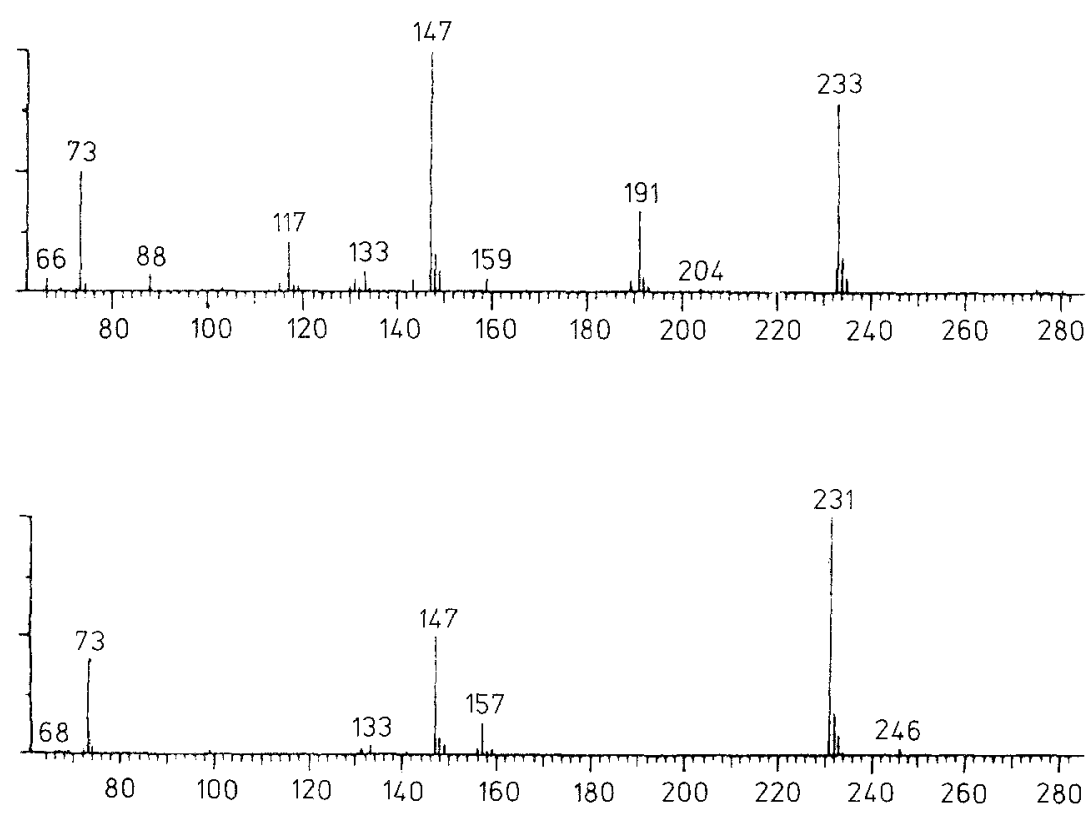

Fig. 2. Mass spectra of the trimethylsilyl derivatives of acetoacetate (lower part) and $D-\beta$-hydroxybutyrate (upper part). The ions of $\mathrm{m} / \mathrm{z} 231$ for acetoacetate and 233 for $\beta$-hydroxybutyrate represent the molecular ions less a methyl group and were used for the determination of ketone body enrichment 

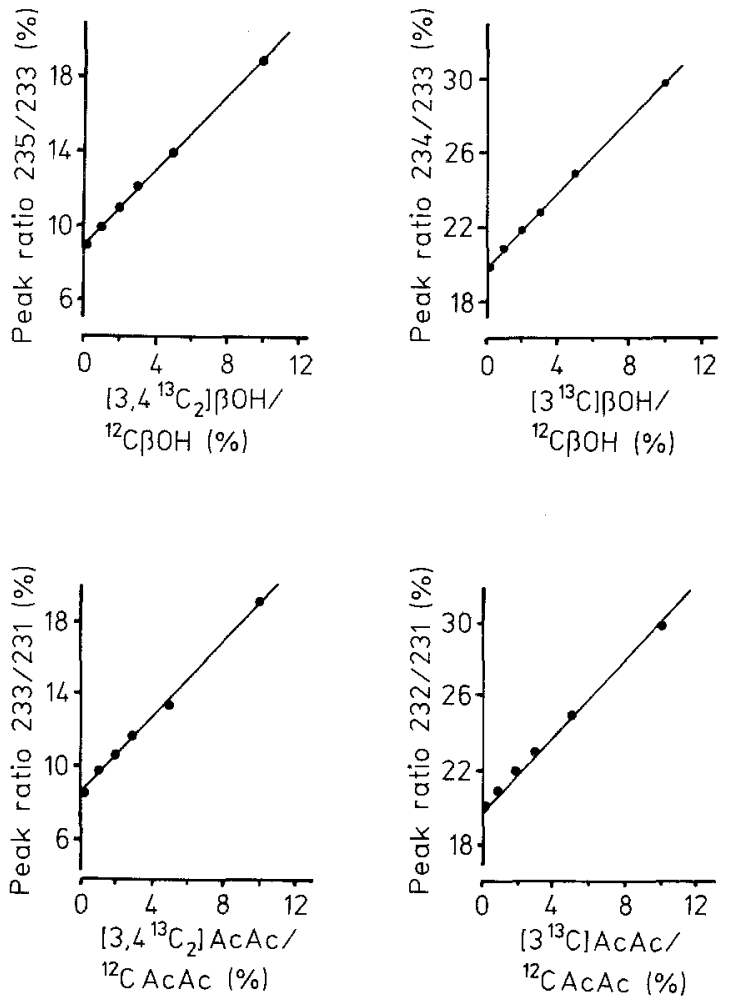

Fig. 3. Standard curves used for the determination from peak ratios of the ratios of labelled $\left({ }^{13} \mathrm{C}\right)$ over natural $\left({ }^{12} \mathrm{C}\right)$ acetoacetate (lower part) and $\mathrm{D}-\beta$-hydroxybutyrate (upper part) using either $\left[3,4-{ }^{13} \mathrm{C} 2\right]-$ labelled tracer (left part) or $\left[3-{ }^{13} \mathrm{C}\right.$-labelled tracer (right part). $r=0.999$ for each standard curve. Due to the natural abundance of stable isotopes in the ditrimethylsilyl derivatives of ketone bodies (mainly ${ }^{29} \mathrm{~S} 1$, ${ }^{30} \mathrm{~S} 1$ and ${ }^{13} \mathrm{C}$ ) the intercepts (peak ratios for a labelled over natural ketone bodies ratio of zero) of the standard curves are $8.86(235 / 233)$ and $8.76(233 / 231)$ when using $\left[3,4-{ }^{13} \mathrm{C} 2\right]$ labelled tracer (theoretical value 8.89 ). When using $\left[3-{ }^{13} \mathrm{C}\right]$ labelled tracer the intercepts are 19.85 $(234 / 233)$ and $19.96(232 / 231)$ (theoretical value: 19.90$)$
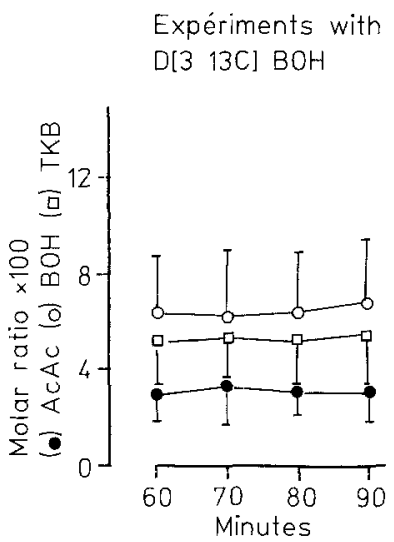

Expériments with

$\left[3,413 \mathrm{C}_{2}\right] \mathrm{AA}$

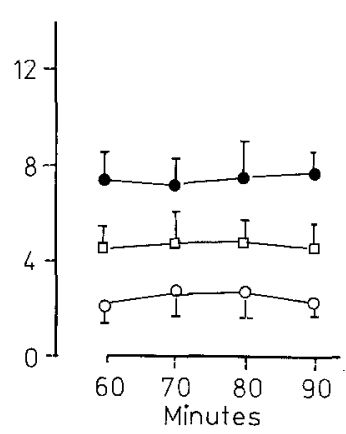

Fig.4. Molar ratios observed in acetoacetate ( ), $\beta$-hydroxybutyrate $(\mathrm{O}-\mathrm{O})$ and total ketone bodies $(\square \square \square)$ following infusion with the labelled tracers $\mathrm{D}\left[3-{ }^{13} \mathrm{C}\right] \beta$-hydroxybutyrate, $\left[3,4-{ }^{13} \mathrm{C} 2\right]$ acetoacetate in the post-absorptive state. Infusion of the tracer was started at time 0 . Stable levels were obtained from 60 to $90 \mathrm{~min}$

toacetate was assayed within $8 \mathrm{~h}$. Immunoreactive insulin (IRI) and glucagon (IRG) were determined $[12,13]$ on plasma kept frozen until the day of the assay. Blood for glucagon determination was collected in tubes containing EDTA and trasylol. Plasma non-esterified fatty acids (NEFA) were determined enzymatically [14].
For determination of the isotopic enrichment of acetoacetate and D- $\beta$-hydroxybutyrate, $2 \mathrm{ml}$ of blood were collected on ice cold perchloric acid (6\%) and centrifuged immediately. The neutralized supernatant was stored frozen until analysis. Two procedures were used. For most samples, $1 \mathrm{ml}$ aliquots were acidified to $\mathrm{pH} 1$ with $\mathrm{HCL}$, mixed with $9 \mathrm{ml}$ of ethyl acetate (Prolabo, Paris, France) and shaken vigorously for $60 \mathrm{~s}$. After separation, the organic phase was evaporated to dryness under a stream of $\mathrm{N}_{2}$ at room temperature prior to derivatization. For some samples, $1 \mathrm{ml}$ of sample was placed on an anion exchange resin column (AG1X8 formate form, Biorad, Richmond, CA, USA), the resin washed with deionized water $(3 \mathrm{ml})$ and acetoacetate and $\beta$-hydroxybutyrate eluted with perchloric acid $(1 \mathrm{ml})$. After neutralization and centrifugation the eluate was lyophilized before derivatization. Similar results were obtained with both methods. Derivatives were synthesised by adding pyridine $(20 \mu \mathrm{l}$, Pierce Chemical Company, Rockford, IL, USA) and bis(trimethylsilyl)trifluoracetamide $(20 \mu \mathrm{l})$ with $1 \%$ of trimethylchlorosilane (Pierce Chemical Company) at room temperature. Aliquots $(1 \mu \mathrm{I})$ were injected into a gas chromatograph (Fractovap 4160, Carlo Erba) coupled with a mass spectrometer (Quadrupole R 10-10, Nermag, Rueil Malmaison, France) and equipped with a $10 \mathrm{~m}$ fused silica capillary column coated with CP Sil 19 CB (Chrompack Inc., Bridgewater, NJ, USA).

The operating conditions were as follows: injector temperature $170^{\circ} \mathrm{C}$, oven temperature $50^{\circ} \mathrm{C}$ for $4 \mathrm{~min}$ increasing by $5^{\circ} / \mathrm{min}$; split ratio $1 / 10$, interface temperature $180-200^{\circ} \mathrm{C}$, source temperature $200^{\circ} \mathrm{C}$. Fragmentation of the molecule was performed by electron impact $(70 \mathrm{ev})$ and the following ions were selectively traced: $\mathrm{m} / \mathrm{z} 231$, 232,233 for acetoacetate and $233,234,235$ for $D-\beta$-hydroxybutyrate.

\section{Calculations}

The peak area ratios $(\mathrm{m} / \mathrm{z} 232 / 231$ and $233 / 231$ for acetoacetate and $\mathrm{m} / \mathrm{z} 234 / 233$ and $235 / 233$ for $\beta$-hydroxybutyrate) were calculated and the corresponding molar ratios were determined from standard curves prepared by mixing weighed amounts of natural and ${ }^{13} \mathrm{C}-\mathrm{la}-$ belled acetoacetate and $\beta$-hydroxybutyrate (see Results) before calculation of the moles percent enrichment (MPE) of blood acetoacetate and D- $\beta$-hydroxybutyrate [MPE $\equiv$ tracer/(tracer + tracee)]. At steadystate the appearance rates $\left(\mu \mathrm{mol} \cdot \mathrm{kg}^{-1} \cdot \mathrm{min}^{-1}\right)$ of total ketone bodies (TKB) were calculated by the formula:

$$
\text { TKB Ra }=\frac{F}{\frac{\text { MPE A }[\mathrm{A}]+\text { MPE B }[\mathrm{B}]}{[\mathrm{A}]+[\mathrm{B}]}}-\mathrm{F}
$$

where $F$ is the isotope infusion rate $\left(\mu \mathrm{mol} \cdot \mathrm{kg}^{-1} \cdot \mathrm{min}^{-1}\right),[A]$ and $[B]$ are the concentrations of acetoacetate and $\beta$-hydroxybutyrate $(\mu \mathrm{mol} /$ I), and MPE A and MPE B are the moles percent enrichments of acetoacetate and $D$ - $\beta$-hydroxybutyrate.

$$
\text { In this formula the term } \frac{\text { MPE A }[\mathrm{A}]+\mathrm{MPE} B[\mathrm{~B}]}{[\mathrm{A}]+[\mathrm{B}]} \text { represents "to- }
$$

tal ketone body moles percent enrichment", an expression analogous to the "total ketone body specific activity" used for radioactive tracers [2-7].

During non steady-state conditions the appearance and disappearance rates of acetoacetate, D- $\beta$-hydroxybutyrate and total ketone bodies were calculated using the modified Steele's equations:

$\mathrm{Ra}=\frac{\mathrm{F}-\frac{\mathrm{pV}(\mathrm{C} 2+\mathrm{C} 1)}{2} \times \frac{(\mathrm{MPE} 2-\mathrm{MPE} 1)}{\mathrm{t} 2-\mathrm{t} 1}}{\frac{\mathrm{MPE} 2+\mathrm{MPE} 1}{2}}-\mathrm{F}$

$\mathrm{Rd}=\mathrm{Ra}-\frac{\mathrm{pV}(\mathrm{C} 2-\mathrm{C} 1)}{\mathrm{t} 2-\mathrm{t} 1}$

where $\mathrm{V}$ is the volume of distribution, $\mathrm{p}$ the functional pool fraction, $\mathrm{t} 1$ and $\mathrm{t} 2$ represent two different sampling points; $\mathrm{C} 2$ and $\mathrm{C} 1$ and MPE2 and MPE1 represent concentrations and MPE at $t 2$ and $t 1$ of 
Table 1. Individual values in the post-absorptive state of the concentrations of ketone bodies, NEFA and of the appearance rate (Ra) of total ketone bodies (TKB) of the four subjects studied

\begin{tabular}{|c|c|c|c|c|c|c|c|c|}
\hline \multirow[t]{2}{*}{ Subjects } & \multicolumn{4}{|c|}{ Tests with $\left[3,4-{ }^{13} \mathrm{C}_{2}\right]$ acetoacetate } & \multicolumn{4}{|c|}{ Tests with $\left[3-{ }^{13} \mathrm{C}\right] \mathrm{D}-\beta$-hydroxybutyrate } \\
\hline & $\begin{array}{l}\text { Acetoacetate } \\
(\mu \mathrm{mol} / 1)\end{array}$ & $\begin{array}{l}\text { D- } \beta \text {-hydroxy- } \\
\text { butyrate } \\
(\mu \mathrm{mol} / \mathrm{l})\end{array}$ & $\begin{array}{l}\text { NEFA } \\
(\mu \mathrm{mol} / 1)\end{array}$ & $\begin{array}{l}\text { Ra TKB } \\
\left(\mu \mathrm{mol} \cdot \mathrm{kg}^{-1} \cdot \min ^{-1}\right)\end{array}$ & $\begin{array}{l}\text { Acetoacetate } \\
(\mu \mathrm{mol} / 1)\end{array}$ & $\begin{array}{l}\text { D- } \beta \text {-hydroxy- } \\
\text { butyrate } \\
(\mu \mathrm{mol} / \mathrm{l})\end{array}$ & $\begin{array}{l}\text { NEFA } \\
(\mu \mathrm{mol} / 1)\end{array}$ & $\begin{array}{l}\mathrm{Ra} \text { TKB } \\
\left(\mu \mathrm{mol} \cdot \mathrm{kg}^{-1} \cdot \mathrm{min}^{-1}\right)\end{array}$ \\
\hline 1 & 96 & 280 & 419 & 4.50 & 75 & 164 & 310 & 2.45 \\
\hline 2 & 26 & 50 & 290 & 2.52 & 80 & 123 & 380 & 2.49 \\
\hline 3 & 65 & 108 & 386 & 3.50 & 40 & 102 & 235 & 2.76 \\
\hline 4 & 72 & 150 & 520 & 4.45 & 32 & 45 & 296 & 2.18 \\
\hline
\end{tabular}

acetoacetate, D- $\beta$-hydroxybutyrate or TKB as appropriate. The values of $\mathrm{p}$ and $\mathrm{V}$ used for calculations were 1 and $0.201 / \mathrm{kg}$ of body weight as previously established by Keller et al. [5].

\section{Statistical analysis}

Results are shown as individual values or mean and standard error of the mean. Correlations were established by the least square method. Comparisons were performed using Student's t-test for paired values.

\section{Results}

\section{Gas chromatography-mass spectrometry procedures}

A total ion chromatogram and the mass spectra of the trimethylsilyl derivatives of a standard of mixed acetoacetate and D- $\beta$-hydroxybutyrate are shown in Figures 1 and 2 respectively. The two peaks of acetoacetate have identical mass spectra (these two peaks represent probably the formation of tautomeric isomers due to the 2,3 double bond formation [9]). In preliminary experiments (standard curves and determinations of in vivo enrichment) the same results were obtained using either of these two peaks. The peak of greater abundance was therefore used. There was a small molecular ion for acetoacetate but not for $\beta$-hydroxybutyrate. The ions of $\mathrm{m} / \mathrm{z} 231$ for acetoacetate and 233 for $\beta$-hydroxybutyrate correspond to the molecular ion $(\mathrm{m} / \mathrm{z}$ respectively 246 and 248$)$ minus a methyl group $(\mathrm{m} / \mathrm{z} 15)$. These ions were used for the determination of enrichment. During the tests with $\left[3,4-{ }^{13} \mathrm{C} 2\right]$ acetoacetate, the ions 231 and 233 , and 233 and 235 , were selectively monitored for acetoacetate and D- $\beta$-hydroxybutyrate respectively. For the tests with $\left[3{ }^{13} \mathrm{C}\right] \mathrm{D}-\beta$-hydroxybutyrate the ions monitored were 231 and 232 for acetoacetate and 233 and 234 for D- $\beta$-hydroxybutyrate. The natural enrichments of acetoacetate and $\beta$-hydroxybutyrate isolated from blood prior to infusion of tracer were identical to those obtained from unenriched standard. Accurate determinations of peak area ratios could be obtained for concentrations of ketone bodies as low as $15 \mu \mathrm{mol} / 1$. Intraassay coefficients of variation were $1 \%$ or less for the peak ratios $232 / 231$ and $234 / 233$ and $1.5 \%$ for the ratios $233 / 231$ and $235 / 233$. Corresponding interassay coefficients of variation were respectively $3.8 \%$ and $5.1 \%$. These coefficients of varia- tion were determined using blood samples. Thereafter all blood samples of each test were assayed within the same series. Linear standard curves for acetoacetate and $\beta$-hydroxybutyrate were obtained using solutions of known enrichment (Fig. 3).

\section{In vivo studies}

During the infusion in the post-absorptive state of labelled acetoacetate or D- $\beta$-hydroxybutyrate, stable levels of concentration and enrichment were obtained for both ketone bodies from $60 \mathrm{~min}$ to $90 \mathrm{~min}$ (Fig. 4), thus permitting the use of formulae for steady-state conditions for determination of flux. However, as previously observed with ${ }^{14} \mathrm{C}$ labelled ketone bodies, there was an isotopic disequilibrium between acetoacetate and D- $\beta$ hydroxybutyrate. The calculated appearance rate of TKB during both experiments are shown in Table 1. The values of TKB appearance rates obtained during the tests with $\left[3-{ }^{13} \mathrm{C}\right] \mathrm{D}-\beta$-hydroxybutyrate $(2.76 \pm 0.14$ $\mathrm{pmol} \cdot \mathrm{kg}^{-1} \cdot \mathrm{min}^{-1}$ ) were slightly lower than those found during the tests with labelled AcAc (3.74 \pm 0.46 $\mu \mathrm{mol} \cdot \mathrm{kg}^{-1} \cdot \min ^{-1}$ ). However, plasma NEFA were also lower and there was a direct relationship between plasma NEFA concentration and TKB production rate $(r=0.784, p<0.05)$.

Subsequent infusion of natural acetoacetate resulted in a decrease of NEFA levels (Table 2). The small decrease of blood glucose was not significant, and there were no detectable changes of immunoreactive insulin and glucagon concentrations.

During the experiments with $\left[3,4-{ }^{13} \mathrm{C} 2\right]$ acetoacetate (Fig.5) the infusion of natural acetoacetate decreased the enrichment of both ketone bodies so that the enrichments of acetoacetate and D- $\beta$-hydroxybutyrate became almost identical. The actual infusion rates of acetoacetate were $7.3 \pm 0.3,14.5 \pm 0.8,21.9 \pm 1.2$ and $10.9 \pm 0.6 \mu \mathrm{mol} \cdot \mathrm{kg}^{-1} \cdot \mathrm{min}^{-1}$, whereas the isotopically determined appearance rates were, at the end of each period of infusion, respectively $8.2 \pm 0.7,14.0 \pm 0.3$, $23.0 \pm 1.7$ and $9.8 \pm 0.8 \mu \mathrm{mol} \cdot \mathrm{kg}^{-1} \cdot \mathrm{min}^{-1}$ for acetoacetate and $9.2 \pm 1.0,16.3 \pm 0.7,23.1 \pm 1.1$ and $10.7 \pm 0.8$ $\mu \mathrm{mol} \cdot \mathrm{kg}^{-1} \cdot \mathrm{min}^{-1}$ for TKB. Thus, as previously found with ${ }^{14} \mathrm{C}$ labelled tracers [4], the maximal $\mathrm{Ra}$ values of acetoacetate and TKB were less than the sum of their basal values and the maximal rate of infusion of ace- 


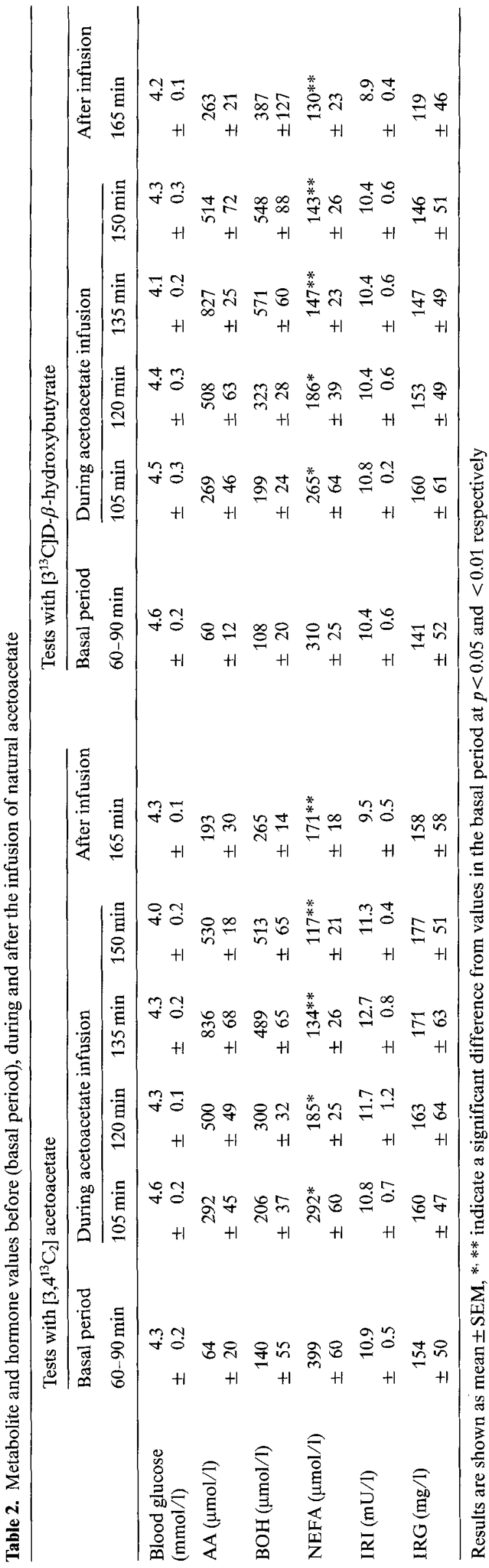

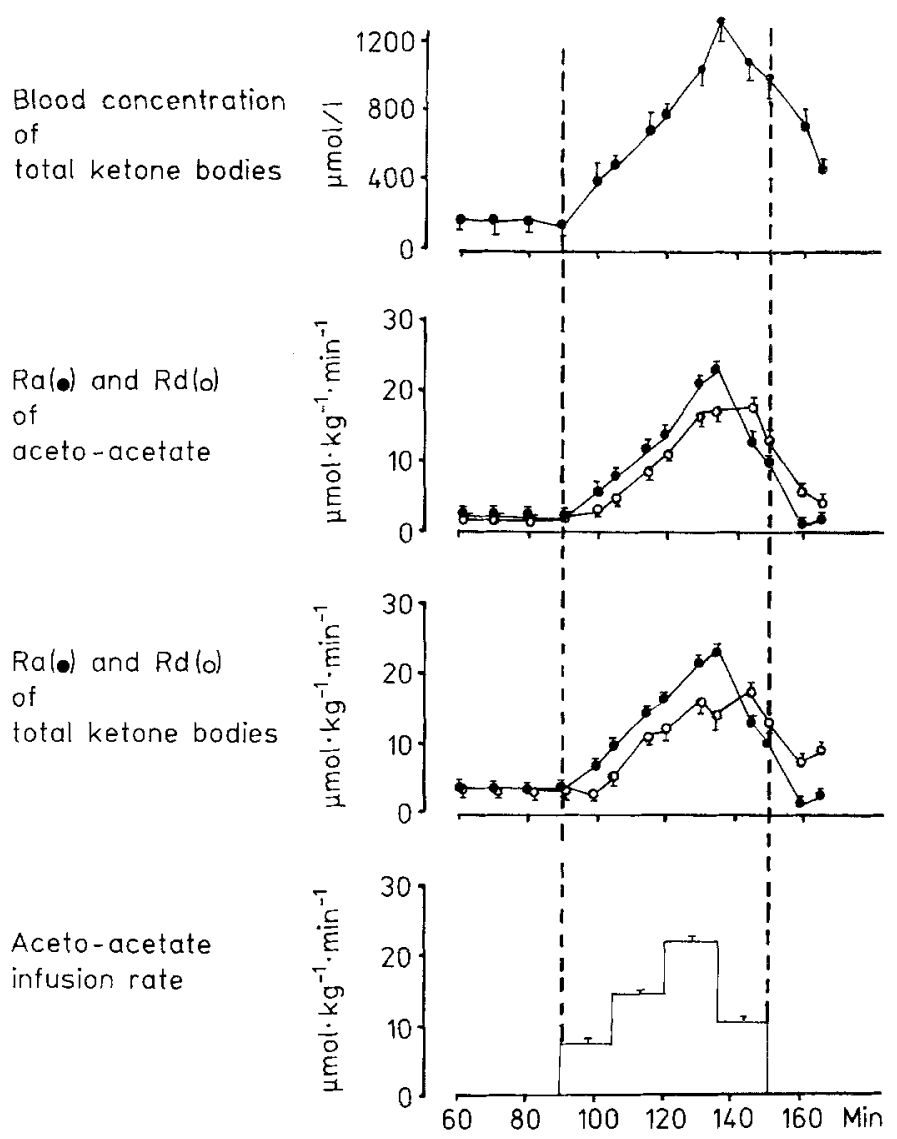

Fig.5. Total ketone body (TKB) concentrations and the isotopically determined appearance rate $(\mathrm{Ra}, \boldsymbol{O})$ and disappearance rate $(\mathrm{Rd}, \mathrm{O})$ of acetoacetate and TKB in four subjects before and during the infusion of natural acetoacetate; experiments with $\left[3,4-{ }^{13} \mathrm{C} 2\right]$ acetoacetate

toacetate. Examination of the individual values showed a highly significant relation between the infusion rates of acetoacetate and the isotopically determined $\mathrm{Ra}$ of either acetoacetate $(r=0.94, p<0.001)$ or TKB $(r=0.96$, $p<0.001)$. Comparable results were obtained during the tests with [3-13C]D- $\beta$-hydroxybutyrate (Fig. 6). The infusion of natural acetoacetate also decreased the enrichment of both ketone bodies. The difference of enrichment between acetoacetate and D- $\beta$-hydroxybutyrate first increased slightly and then decreased progressively to near disappearance at the end of the test. The actual infusion rates of acetoacetate were successively $8.4 \pm 0.5, \quad 16.8 \pm 0.9,25.2 \pm 1.4$ and $12.6 \pm 0.8 \mu \mathrm{mol}$. $\mathrm{kg}^{-1} \cdot \mathrm{min}^{-1}$, whereas the isotopically determined $\mathrm{Ra}$ of $\mathrm{TKB}$ at the end of each infusion step were $11.1 \pm 1.7$, $16.7 \pm 0.7, \quad 25.0 \pm 1.1$ and $11.1 \pm 0.7 \mu \mathrm{g} \cdot \mathrm{kg}^{-1} \cdot \mathrm{min}^{-1}$. Thus the maximal value of TKB $\mathrm{Ra}$ was again less than the sum of basal $\mathrm{Ra}$ value and maximum acetoacetate infusion rate. Examination of the individual values showed a highly significant relationship between acetoacetate infusion rates and isotopically determined $\mathrm{Ra}$ values of TKB $(r=0.96, p<0.001)$. The production rate of $\mathrm{D}$ - $\beta$-hydroxybutyrate rose from a basal value of $1.95 \pm 0.20 \mu \mathrm{g} \cdot \mathrm{kg}^{-1} \cdot \min ^{-1}$ to a maximal value of $11.6+0.6 \mu \mathrm{g} \cdot \mathrm{kg}^{-1} \cdot \mathrm{min}^{-1}$, showing that a large part of 


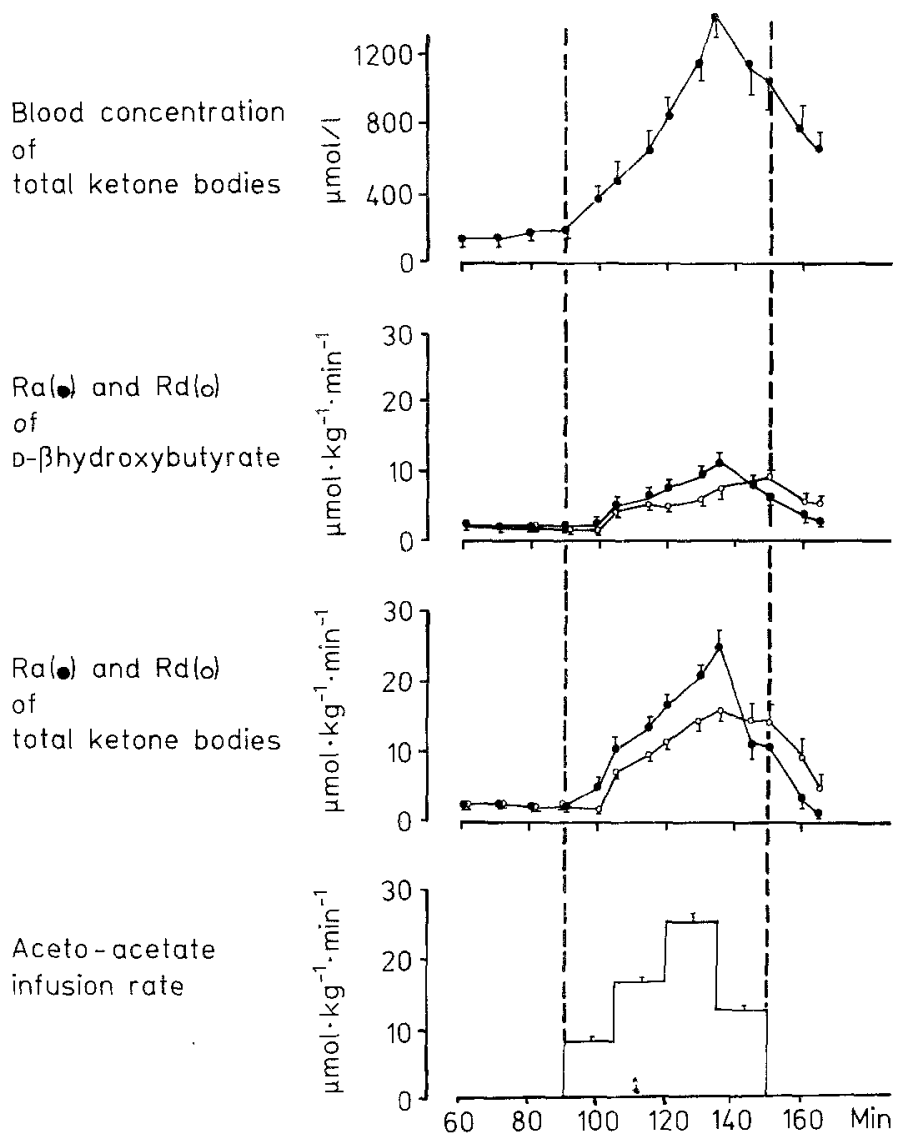

Fig. 6. Total ketone body (TKB) concentrations and the isotopically determined appearance rate $(\mathrm{Ra}, \mathrm{O})$ and disappearance rate $(\mathrm{Rd}, \mathrm{O})$ of $\mathrm{D}$ - $\beta$-hydroxybutyrate and TKB in four subjects before and during the infusion of natural acetoacetate. Experiments with $\left[3-{ }^{13} \mathrm{C}\right] \mathrm{D}-\beta$-hydroxybutyrate

the infused acetoacetate was converted into D- $\beta$-hydroxybutyrate.

\section{Discussion}

In the present work we have developed a method for the determination of ketone body kinetics using stableisotope labelled tracers and GC/MS systems. We have tested the usefulness of two different tracers, ${ }^{13} \mathrm{C}$ labelled acetoacetate and D- $\beta$-hydroxybutyrate, and found similar results using either compound. Labelled D- $\beta$-hydroxybutyrate has the advantage of stability, whereas acetoacetate is subject to spontaneous decarboxylation, but its preparation is tedious and time-consuming. Recently, Miles et al. [9] have published another method using stable isotopes for the determination of ketone body kinetics in dogs, but have not used it in man nor validated it for non steady-state conditions. Our method is relatively simple, not too time-consuming and allows determination of the enrichment even for the low ketone body levels of the post-absorptive state. The total innocuity of stable isotopes makes it possible to perform repetitive studies in adults and to conduct studies in pregnant women and children. The blood volume used, although relatively large, could be easily reduced for this last purpose.

It was impossible to compare our results with values obtained in the same subjects using ${ }^{14} \mathrm{C}$ labelled tracers, since the use of radioactive tracers for metabolic studies in normal subjects is not authorized in France. However, the TKB appearance rates in the post-absorptive state that we obtained in normal humans are consistent with previous results obtained using ${ }^{14} \mathrm{C}$ labelled acetoacetate or D- $\beta$-hydroxybutyrate. Miles et al. [15] report mean values of TKB production of 1.5 to $2.2 \mu \mathrm{mol} \cdot \mathrm{kg}^{-1} \cdot \mathrm{min}^{-1}$, and Fery and Balasse [16] of $3.46 \mu \mathrm{mol} \cdot \mathrm{kg}^{-1} \cdot \mathrm{min}^{-1}$. Keller and Sonnenberg $[4,17]$ found slightly higher values $\left(6 \mu \mathrm{mol} \cdot \mathrm{kg}^{-1} \cdot \mathrm{min}^{-1}\right)$, but their subjects also had slightly higher TKB levels, and there is a direct relationship between TKB production and levels [18].

For determination of ketone body kinetics during the non steady-state, we have used a one pool model comparable to that used during experiments with ${ }^{14} \mathrm{Cla}$ belled tracers [2-6]. The values of the volume of distribution and of the functional pool fraction used for the calculations were those previously established by Keller et al. [4] in normal humans. However, since these measurements were performed in post-absorptive normal subjects, use of this model in other situations would require prior determination of the effective distribution volume by the bolus injection technique. Using this single pool model we found a good agreement between the isotopically determined appearance rate of ketone bodies and the infusion rate of natural acetoacetate. Indeed, the calculated TKB appearance rates were slightly higher that the actual infusion rates of acetoacetate for the first infusion step in the experiments with labelled D- $\beta$-hydroxybutyrate and for the first and second infusion steps during tests with labelled acetoacetate. However, during the infusion of exogenous acetoacetate the TKB production is the sum of the endogenous production and of the infusion. There is evidence that endogenous ketone body production is decreased at least in part during infusion of ketone bodies $[2,4]$. This possibility is supported, at least for the highest infusion rates, by the fall of NEFA levels observed in the present experiments as well as in previous studies $[4,19]$. Moreover, although we failed to detect an increase of peripheral insulin concentration in the present studies, there is evidence that high ketone body levels can stimulate insulin secretion [19]. However, it is likely that some endogenous ketone body production persisted, especially during the initial infusion steps of natural acetoacetate; this could explain in part the small discrepancies between the isotopically determined appearance rates of TKB and the infusion rates of exogenous AcAc.

Using either stable or radioactive isotopic tracers, one of the problems involved in the determination of ketone body kinetics is the lack of isotopic equilibrium 
between acetoacetate and D- $\beta$-hydroxybutyrate. This disequilibrium is more evident in situations with low ketone body levels and less apparent when concentrations are raised to high values [3]. A common approach to circumvent this difficulty when using ${ }^{14} \mathrm{C}$ labelled tracers is to calculate the "total ketone body specific activity". We used a similar approach by calculating the "total moles percent enrichment". Such an approach has been criticised on theoretical grounds [20]. It has been suggested that either separate injections of labelled acetoacetate and D- $\beta$-hydroxybutyrate at different times or the simultaneous administration of doubly labelled ketone bodies would provide more accurate results. The first possibility has been employed by Cobelli et al. [21], but is limited to steady-state conditions and requires the assumption that the metabolic state of the subject is the same during the two experiments. Preliminary results of studies in dogs using a double label with both stable and radioactive isotopes have been presented recently [22], and suggest that this approach could provide more accurate results. Theoretically, such an approach could also be used by combining the infusions of two differently labelled stable tracers. However, the present experiments, as well as previous studies with ${ }^{14} \mathrm{C}$ labelled tracers, show that reasonable estimates of ketone body kinetics can be performed using a simpler approach. In conclusion, the present method appears useful for studies of ketone body metabolism in humans in both steady- and non steady-state conditions.

Acknowledgments. We wish to thank Ms. A. Blanc and Ms. M.Odéon for their excellent technical assistance, J.L.Brazier, M. Desage and R. Guilluy for their help in the course of this study and Ms. S. Terfous for her secretarial work. We also thank Ms. Bureau for her help in the preparation of the infusates.

\section{References}

1. Robinson AM, Williamson DH (1980) Physiological role of ketone bodies as substrates and signals in mammalian tissues. Physiol Rev 60: 143-187

2. Balasse EO, Neef MA (1975) Inhibition of ketogenesis by ketone bodies in fasting humans. Metabolism 24: 999-1007

3. Balasse EO (1979) Kinetics of ketone body metabolism in fasting humans. Metabolism 28: 41-50

4. Keller U, Sonnenberg GE, Stauffacher W (1981) Validation of a tracer technique to determine non steady state ketone body turnover rates in man. Am J Physiol 240: E 253-E 262

5. Miles JM, Haymond MW, Rizza RA, Gerich JE (1980) Determination of ${ }^{14} \mathrm{C}$ radioactivity in ketone bodies: a new, simplified method and its validation. J Lipid Res 21: 646-650

6. Miles JM, Rizza RA, Haymond MW, Gerich JE (1980) Effects of acute insulin deficiency on glucose and ketone body turnover in man. Evidence for the primacy of overproduction of glucose and ketone bodies in the genesis of diabetic ketoacidosis. Diabetes 29: 926-930

7. Reichard GA, Owen OE, Haff AC, Paul P, Bortz WM (1974) Ketone body production and oxidation in fasting obese humans. $J$ Clin Invest 53: 508-515

8. Keller U, Cherrington AD, Liljenquist JE (1978) Ketone body turnover and net hepatic ketone production in fasted and in diabetic dogs. Am J Physiol 235: E 238-E 247

9. Miles JM, Schwenk F, McClean KL, Haymond MW (1984) Determination of ketone body turnover in vivo with stable isotopes utilizing gas chromatography/mass spectrometry. Anal Biochem $141: 110-115$

10. Sonnenberg GE, Keller U (1982) Sampling of arterialized heated hand venous blood as a non-invasive technique for the study of ketone body kinetics in man. Metabolism 31: 1-5

11. Beylot M, Riou JP, Bienvenu F, Mornex R (1980) Increased ketonaemia in hyperthyroidism. Evidence for a beta-adrenergic mechanism. Diabetologia 19: 505-510

12. Hales CM, Randle PJ (1963) Immunoassay of insulin with insulin antibody precipitate. Biochem J 88: 137-148

13. Harris J, Faloona GR, Unger RH (1979) Glucagon. In: Jaffe BM, Behrman HR (eds) Methods of hormone radioimmunoassay. Academic Press, New York, pp 643-671

14. Okabe H, Uji Y, Nagashima K, Noha A (1980) Enzymic determination of free fatty acids in serum. Clin Chem 26:11-15

15. Miles JE, Haymond MW, Nissen SL, Gerich JE (1983) Effects of free fatty acids availability, glucagon excess, and insulin deficiency on ketone body production in post-absorptive man. J Clin Invest $71: 1554-1561$

16. Fery F, Balasse EO (1983) Ketone body turnover during and after exercise in overnight fasted and starved humans. Am J Physiol 245: E 318-E 325

17. Sonnenberg GE, Stauffacher W, Keller U (1982) Failure of glucagon to stimulate ketone body production during acute insudeficiency or insulin replacement in man. Diabetologia 23: 94-100

18. Balasse EO, Fery F (1983) Aspects of ketone body metabolism in normal and diabetic subjects at rest and during exercise. In: Crepaldi G, Lefebvre PJ, Galton DJ (eds) Diabetes, obesity and hyperlipidemias, vol II. Academic Press, London, pp 249-255

19. Miles JE, Haymond MW, Gerich JE (1981) Suppression of glucose production and stimulation of insulin secretion by physiological concentrations of ketone bodies in man. J Clin Endocrinol Metab 52: 34-37

20. Barton RN (1980) Isotopic study of ketone body kinetics: invalidity of calculations based upon specific activity of total ketone bodies. Metabolism 29: 392-394

21. Cobelli C, Nosadini R, Toffolo G, McCulloch A, Avogaro A, Tiengo A, Alberti KGGM (1982) Model of the kinetics of ketone bodies in humans. Am J Physiol 243: R 7-R 17

22. Miles J, Schwenk W, Gerich J, Haymond M (1984) Are conventional isotopic methods for determination of in vivo ketone body kinetics valid? 7th International Congress of Endocrinology, July 1-7, Quebec City, Canada (Abstract)

Received: 20 May 1985

and in revised form: 14 October 1985

M. Beylot

INSERM U.197, Faculté de Médecine Alexis Carrel

rue G.Paradin

F-69372 Lyon Cédex 08, France 